\title{
Application status and Prospect Analysis of digital design and manufacturing technology of mold
}

\author{
Liang Tianyu \\ Dalian Vocational \& Technical College, Liaoning Dalian, 116035
}

Keywords: Mold; digital design; manufacturing network;

\begin{abstract}
The digital mold design and manufacturing technology has the advantages of simple operation and high data processing efficiency, and has been widely used in the manufacturing industry. The digital design and manufacturing technology of die is applied to the development and application of rapid design system, and the function of CAE and PDM technology is prominent. At the same time, mold design and manufacture depend more on digital simulation. In the future development, digital mold design and manufacturing will be more green, networked direction, mold MBD technology to accelerate the promotion of digital flexible die more widely used in aerospace enterprises.
\end{abstract}

\section{Introduction}

The mold is refers through the structure specific through a certain way of the structure forming material, has been widely used in aerospace, machinery manufacturing and other industries, and mold digital design and manufacturing technology refers to the digital product development and utilization of network information technology in manufacturing [1]. With the rapid development of economy and society and the progress of urbanization in China in recent years, digital mold design and manufacturing technology has been widely used, and effectively promoted the progress of China's manufacturing industry. Digital design and manufacturing technology of mold has the advantages of simple operation, simple design and digital processing efficiency, the development of faster, but because the software engineering technology in China should be improved, the high-end engineering software for digital design of China's mold manufacturing technology relies mostly on technical input foreign software company. Digital mold design and manufacturing process mainly includes two aspects process design and structure design, it should be a detailed analysis of the existing process, and puts forward some suggestions for improvement of scientific and reasonable, and the application of digital manufacturing technology of mold design and meticulous observation, on the basis of the future development of the scientific and rational planning, further development to promote the digital design and manufacturing technology.

\section{Digital mold design and manufacturing technology}

The rise of the manufacturing industry in the middle of last century, with the birth of the first CNC machine tool as a symbol, has undergone many stages of transformation and upgrading, and the development is becoming mature. The development of network information technology and the wide application of digital technology bring new opportunities to the manufacturing industry, and provide a better platform for technological improvement and improvement. China's introduction of 
digital design and manufacturing technology of mold in the last century in 80s, because of its simple operation, data processing speed and design efficiency, especially in various sectors of China's manufacturing industry has been widely used. Mould digital design and manufacturing is the process of creating a knowledge driven, including not only on the existing knowledge integration, management and innovation, but also improve and reasonable application of network information technology and the digital simulation technology improvement. Digital design and manufacturing technology of mold manufacturing industry has become the core competitive factors, how will the existing resources and technology to transform traditional industries for the design and manufacture of advanced technology has become urgent to solve the problem of manufacturing industry. At present, digital design and manufacturing technology of our country mould there are still some problems related to software engineering technology is not perfect, can not meet the needs of digital design and mold manufacturing, often rely on foreign software technology, at the same time, China's mold design and manufacture of digital still lack of numerical integration and knowledge integration technology in many fields also, should be carried out by the appropriate improvement and perfection, promote our country manufacturing industry to achieve further development[2].

\section{Application status of digital mold design and manufacturing technology}

The development and application of rapid design system occupies an important proportion in the development of digital design and manufacturing technology, and it is of great significance to the application and development of digital mold design and manufacturing technology. The first is the rapid stamping mould design, through the combination of 3D CAD technology and knowledge engineering technology, basic technology as a platform for rapid design of stamping die, the platform will die design knowledge, experience of integration and management. At the same time, staff should be scientific and reasonable planning and design of stamping die design process according to the product design and manufacturing requirements, and in strict accordance with the design scheme of the manufacture, production of stamping die quality. Secondly, attention should be paid to the springback correction in hydroforming die, springback of sheet metal parts is bending angle and die because the bomb is not fully fit, cause rebound phenomenon more and complex, has great influence on the molding, shall be for the detailed analysis and put forward reasonable advice. And the reason for the rebound phenomenon and the related calculation formula after a long time of accumulation and amendment, has been revised book, and has some research experience, on this basis, upgrading and transformation of the rapid design system, and promote the further development of digital design and manufacturing technology[3].

CAE is a kind of computer aided engineering, mechanical design and structure analysis is applied to complex engineering in engineering design and analysis of related products, to be able to connect all aspects of the project, and efficient processing and analysis of relevant data, to analyze different forms of digital design mold design and manufacturing technology, such as dynamic analysis linear analysis, [4]. The essence of CAE is a comprehensive multi angle analysis of the complex technology by using the finite element analysis method, not only can make a comprehensive analysis of digital design and die manufacturing technology, but also can locate the technical parameters and process parameters. At the same time, it is necessary to make a detailed analysis of the influence of various process parameters on the forming quality, and to carry out a scientific and rational design and planning of the mold forming. In addition, for some irregular objects and complex objects, CAE analysis technology can carries on the accurate analysis, suitable for ordinary drawing die forming apparatus, and liquid forming as an analytical technique has the 
advantages of simple operation and more advanced and applicable appliance more complex on the surface morphology and shape of higher requirements. CAE analysis technology has been widely used in digital mold design and manufacturing technology, and it can make comprehensive and accurate analysis of related technology and products, so we should strengthen its utilization.

At present, China's digital mold design and manufacturing technology has good prospects for development, at the same time toward more intelligent direction, more dependent on digital simulation. Digital simulation is element to establish a scientific and reasonable mathematical model and load using the power system network, and the mathematical model of experiment and Research on the computer, detailed analysis and Research on digital design and manufacturing technology of mold. Digital simulation technique has certain predictability, mold manufacturing by means of digital simulation technology based on Computational Mathematics, physics and the means of demonstration, carries on the detailed analysis of the manufacturing process and the manufacturing process and the nature of nature, making clear, and the prediction function of mold manufacturing optimization design and control. At present, there are still some problems in the digital processing technology. How to discretize the continuous physical phenomena and the vague and uncertain phenomena has become the urgent problem to be solved in the digital processing technology. Most enterprises have adopted the analysis and research process of geometrical simulation, physical simulation and other means to promote the development of mold manufacturing, mold manufacturing process, with the progress of information technology and digital network, mold manufacturing will be more dependent on digital simulation technology.

PDM is used to manage product related information and production tools, can effectively improve the production efficiency, and meticulous management of the production process, standardize the work flow, has important significance for the application of digital design and manufacturing technology. At the same time, PDM can control the product life cycle scientifically and rationally, make efficient use of all kinds of documents and data, and promote the transformation of the working model, which can effectively improve the molding efficiency of the mold [5]. In recent years, China's rapid economic and social development, city construction progress, information technology and computer network technology has developed rapidly, more and more enterprises have a more in-depth understanding of PDM technology, and realized the importance of manufacturing technology for digital design of molding and mold, strengthen the application of the technology the. At the same time, adding PDM technology also makes more advanced digital design and manufacturing technology of mold more intelligent, strengthen the application of digital design and mold manufacturing technology in the manufacturing industry, to further promote the development of China's manufacturing industry.

\section{Digital mold design, manufacturing technology outlook}

MBD is a kind of method of scientific and reasonable definition of product information and expression, based on 3D solid foundation, has a complete and accurate specification and advantages, the product information attached to the 3D entity model, has been applied widely in [4] digital design and manufacturing in mold. The sign of the development of aerospace industry as the embodiment of the comprehensive national strength and the level of science and technology is an important aspect of global competition among countries, in recent years the international aviation market competition is becoming increasingly fierce, China aviation enterprises to increase the use and promotion of MBD technology, the technology of MBD and improve the appropriate improvement. But compared with developed countries, there are still some problems in the application of MBD technology in our country, not through the production cycle of the product and 
production process, and mold design also often use two-dimensional drawings for product design, digital design has not been popularized and used. This has not only hindered the further development of digital design and manufacturing technology, and not conducive to mold design and molding, restricts the development of China's manufacturing industry, so it should be the definition and management of the MBD model to conduct in-depth research and analysis, strengthen the comprehensive application of 3D model in mold design and manufacture, promote the development and application of digital design mold manufacturing technology.

Skin parts die is an important part of digital design and manufacture, widely used in aerospace enterprise, has the characteristics of small batch and multi varieties, the production cycle is short, commonly used entity model not only pull skin molding, manufacturing time, mold and the high manufacturing cost, in this case the emergence of flexible multi point die very good solution to this problem. A typical flexible die is a skin pulled multi-point die. It has the basic body group that can be adjusted. It is easy to control and easy to operate. At the same time, the electric system is adopted to control, control accurately, and work efficiency is higher. At the same time, compared with the traditional methods, the flexible mold also has the following advantages, not only has the vacuum suction column can digital control and positioning, the column can absorb skin parts production and accurate lattice matching, but also a scientific and reasonable adjustment of skin shape and layout, to realize the precise cutting of skin parts edge blending [6] reasonable of parts and assembly. In addition, the flexible mould can effectively avoid the parts in the assembly process of the two trimming, at the same time due to the omission of cutting steps model, improve work efficiency, simplify the manufacturing process, improves the practicability of skin parts, to promote the further development of digital design and manufacturing technology.

With China's economic and social development and city construction progress, environmental problems become increasingly serious, the manufacturing industry should strengthen the environmental protection in the process of development, so in the mold design and manufacturing technology application should strengthen the protection of the environment, promote the move towards a more green direction. First of all, in aviation manufacturing enterprises, they have higher environmental protection requirements for mold design and molding. They should reduce pollution and emissions, reduce energy consumption, and eliminate outdated and outdated moulds in time. As a die with simple structure and short manufacturing cycle, the die is a common mold in the manufacture of the parts with complicated shapes such as the aircraft's mouth, frame and so on. But as China's mold design and manufacturing technology, the pressure drop model no longer meet the needs of the times, not only the forming parts of poor quality, and pollution is more serious, is not conducive to the development of green mold design and manufacturing, so we should reduce the use of pressure drop model, actively looking for molding method can be replaced, and the molding the existing design and improve the appropriate improvement, promotion of mold design and manufacturing towards the direction of the development of green.

Mould digital design and manufacturing technology is built in the mold manufacturing method of computer technology, the development of network information technology has an important influence on it, so should promote mold design and manufacturing to the direction of network development. First of all, enterprises should actively communicate with each other through the Internet and communicate with each other, and promote the development of digital design and manufacturing technology through learning and drawing on. At the same time, the use of network information technology is convenient and efficient, and it can manage the orders all over the world effectively, so as to realize the design and manufacture in different places and improve the work efficiency. Secondly, the network information technology to improve the efficiency of data 
processing, the key technology of network data access and exchange technology has mold data management technology, can make effective integration of resources around the country, the establishment of different forms and different ways of cooperation. The application of network information technology is also beneficial to the establishment of an agile manufacturing enterprise model, which will contribute to the further development and application of digital mold design and manufacturing technology.

\section{Conclusion}

The digital design and manufacturing technology of mould is to make use of network information technology to design the die scientifically and rationally, and to manufacture in strict accordance with the design plan. It is of great significance to the development of China's manufacturing industry. The digital design of China's mold manufacturing technology has been widely used, the rapid design system has been developed and applied reasonably, enhance the design and application of CAE mold, mold manufacturing process rely more on digital simulation, PDM increasingly prominent role. In the future development, technology promotion and application of die MBD, number digital design and manufacturing technology of flexible die is widely used in aviation industry, mold design and manufacture of more green and network direction.

\section{References}

[1]Zhao C F, Wu D H. Discussion on Application of 3D Printing Technology in Package Printing[J]. Applied Mechanics \& Materials, 2015, 731:300-303.

[2]Cao Y, Yao D. Research and Application of 3D Printing Technology in Water Cold Plate Manufacturing[J]. Aeronautical Manufacturing Technology, 2016.

[3]Maric J, Rodhain F, Barlette Y. Discussion on disruptive Potential of the 3D Printing technology[C]// Information and Communication Technologies in Organizations and Society. 2016.

[4]Genctav A, Genctav M, Tari S. DIFFUSION IS UBIQUITUS: A VOLUME DECOMPOSITION APPLICATION FOR 3D PRINTING[C]// Thermal and Fluids Engineering Summer Conference. 2016.

[5]Nakamura Y, Hayashi C, Ohba M. A STUDY OF THE COST PERFORMANCE ANALYSIS OF A PRIVATE FIRM DEPLOYED 3D PRINTING TECHNOLOGY: AN ACTUAL CASE OF A WIRE MANUFACTURING COMPANY[J]. UtcC International Journal of Business \& Economics, 2015.

[6]Snyder T, Weislogel M, Moeck P, et al. 3D Printing and Additive Manufacturing: 3D Systems Technology Overview and New Applications in Manufacturing, Engineering, Science, and Education[C]// NIP \& Digital Fabrication Conference. 2014. 